\title{
Occurrence of New Psychoactive Substances in Wastewater of Major
}

\section{Chinese Cities}

\author{
Tingting Gao, Peng Du, Zeqiong $\mathrm{Xu}$, Xiqing $\mathrm{Li}^{*}$ \\ Laboratory of Earth Surface Processes, College of Urban and Environmental Sciences, \\ Peking University, 100871, Beijing, P. R. China
}

\begin{abstract}
New psychoactive substances have become increasingly popular across the globe in the recent years, which may cause certain public health issues. In this work, sewage-based epidemiology was applied to examine the use of two synthetic cathinones, mephedrone and methylenedioxypyrovalerone (MDPV), and three piperazines, benzylpiperazine (BZP), trifluoromethylphenylpiperazine (TFMPP), and 1-(3-Chlorophenyl)piperazine (mCPP), across China. Influent wastewater samples were collected from 36 sewage treatment plants (STPs) in 18 major cities that cover all the geographic regions of the country. Effluent samples were also collected from selected STPs to determine removal rates. Mephedrone, TFMPP, and mCPP were below detection limits in all the wastewater samples collected, indicating negligible use of these substances in China. MDPV was detected in wastewater at 13 STPs. However, its loads were less than $1 \mathrm{mg} / 1000 / \mathrm{inh} / \mathrm{d}$ at most of these STPs, indicating low use of this substance. BZP was detected at all the STPs examined, with loads typically falling within the range of 3-10 $\mathrm{mg} / 1000 / \mathrm{inh} / \mathrm{d}$. No clear geographic pattern in BZP occurrence in wastewater was identified. Since BZP in wastewater may also come from its legal sources, whether widespread occurrence of BZP means widespread abuse is yet to be confirmed. Apparent removal of MDPV by wastewater treatment was low $(<25 \%)$, whereas removal of BZP was nearly complete (typically $>95 \%$ ).
\end{abstract}

* Corresponding author, e-mail: xli@ urban.pku.edu.cn, phone/fax: 86-10-62753246 


\section{Introduction}

New psychoactive substances (NPS) are substances that are not scheduled under the Single Convention on Narcotic Drugs of 1961 or the Convention on Psychotropic Substances of 1971 , but it may pose a health threat comparable to that posed by substances listed in those conventions (UNODC, 2013). These substances are produced by slightly modifying the functional groups of the molecules of controlled drugs (e.g., cocaine, amphetamines). They have similar psychoactive effects of traditional drugs but can circumvent law enforcement. In the past few years, a fast growing number of NPS have been sold on illicit drug market. By December 2014, emergence of 541 NPS was reported by 95 member states and territories to United Nations Office of Drug and Crime (UNODC) (UNODC, 2015). In contrast, only 126 NPS were reported in 2009 (UNODC, 2013).

Given the widespread appearance of NPS on illicit drug markets, monitoring its abuse is warranted. However, even monitoring abuse of common illicit drugs is not an easy undertaking, as traditional monitoring methods, such as consumer interviews, medical records, crime statistics, and population survey are time-consuming and involve significant biases (Zuccato et al., 2008). Monitoring NPS abuse is much more challenging as consumption of these substances is so transitory and dynamic (Kinyua et al., 2015).

In the past decade, sewage-based epidemiology (SBE) has emerged as an effective tool to estimate drug prevalence and consumption within a particular population. This approach involves collecting wastewater samples, measuring the concentrations of drug residues or its metabolites, and back-calculating drug loads and consumptions by taking account of wastewater flow rates, community populations, as well as correction factors that account for excretion rates and stabilities of the drugs (Zuccato et al., 2008). It uses objective and quantifiable measures (i.e., drug residue concentrations, wastewater flow rates) and yields reliable and reproducible results. In 
addition, these results can be obtained in near real time as sample collection and analysis can be completed quickly. Thus this approach is particularly suitable to monitor the dynamic appearance and abuse of NPS.

Since its first application by Zuccato et al. in 2004 (Zuccato et al., 2005), SBE has been used to monitor use of traditional illicit drugs in many countries in Europe (Andres-Costa et al., 2014; Baker et al., 2014; Berset et al., 2010; Bramness et al., 2015; Kankaanpää et al., 2014; Karolak et al., 2010; Mackulak et al., 2014; Östman et al., 2014; Repice et al., 2013; van Nuijs et al., 2009), North America (Banta-Green et al., 2009; Bartelt-Hunt et al., 2009; Bisceglia et al., 2010; Brewer et al., 2012; Heuett et al., 2015; Loganathan et al., 2009; Metcalfe et al., 2010; Yargeau et al., 2014), East Asia (Du et al., 2015; Khan et al., 2014; Kim et al., 2015; Lai et al., 2013; Li et al., 2014), and Australia (Irvine et al., 2011; Lai et al., 2015). Recently, a number of studies have also been performed in Europe and Australia to monitoring NPS abuse using the SBE approach (Baker and Kasprzyk-Hordern, 2011; Borova et al., 2015; Castglioni et al., 2015; Chen et al., 2013; Kankaanpää et al., 2014; Kinyua et al., 2015; Mwenesongole et al., 2013; Reid et al., 2014; Thai et al., 2016; van Nuijs et al., 2014). Typically, NPS were detected at low concentrations or even below detection limits in those previous studies (e.g., Kinyua et al., 2015; Borova et al., 2015). The loads of detected NPS were much lower than those of primary drug of abuse (e.g., cocaine, MDMA, amphetamine). For example, the highest MDPV loads found in Finland was 19 mg/day/1000 inhabitants, whereas amphetamine loads in Finnish cities were greater than 100 mg/day/1000 inhabitants (Kankaanpää et al., 2014). The average load of methylone was about four times lower than the average daily load of MDMA in an urban catchment in South East Queensland of Australia (Thai et al., 2016). Since target NPS monitored in these studies varied, systematic comparison of abuse of a particular NPS among different studies was not possible. In addition, removal rates and removal pathways of NPS during wastewater treatment have been rarely examined in the above studies.

China has witnessed rapid increases in illicit drug use in the recent years. The 
number of registered drug users increased by $20 \%$ from about 2.5 million of 2013 to nearly 3 million of 2014 (Office of China National Narcotic Control Commission, 2014;2015). The total seizure of common illicit drugs (heroin, cannabis and cannabis resin, methamphetamine-like drugs, ketamine) has also increased by about $20 \%$, from 42.26 ton of 2013 to 50.4 ton of 2014 (Office of China National Narcotic Control Commission, 2014;2015). New psychoactive substances (e.g., cathinones, piperazines) are also seized in China from time to time, accordingly to the Bureau of Narcotics Control of the Ministry of Public Security (personal communication). It is worth noting that ketamine is categorized by UNODC as a NPS. However this drug has been widely abused in China and its seizure was second only to methamphetamine seizure in the past few years (Office of China National Narcotic Control Commission, 2014;2015). Thus ketamine is really "not new" at all in China.

To date, four SBE studies has been performed in Hong Kong and mainland China to estimate common drug use (Du et al., 2015; Khan et al., 2014; Lai et al., 2013; Li et al., 2014). However, none of these studies examined concentrations of cathinones and piperazines in wastewater in China. The objective of this work was to examine the occurrence and geographic pattern of two synthetic cathinones, mephedrone and MDPV, and three piperazines, BZP, TFMPP, and mCPP, in wastewater across China. Influent wastewater samples were collected from 36 STPs of 18 major cities that cover all the geographic regions of the country. Effluent samples were also collected from selected STPs to determine removal rates. This study represents the first nationwide reconnaissance dedicated specifically to NPS abuse in China.

\section{Materials and Methods}

\subsection{Sample collection}

Wastewater samples were collected from 18 major cities that cover all the seven geographic regions of China: Haerbin (HRB) and Dalian (DL) of Northeast; Lanzhou (LZ), Xi-an (XA), and Yinchuan(YC) of Northwest, Beijing (BJ), Changzhi (CZ), and Taiyuan (TY) of North, Luoyang (LY) and Wuhan (WH) of Central China; Shanghai 
(SH), Qingdao (QD), Xiamen (XM), and Suzhou (SuZ) of East, Guangzhou (GZ), Nanning (NN), and Shenzhen (SZ) of South; Chengdu (CD) of Southwest (Figure S1). The majority (11 of total 18) of the cities are provincial capitals or are under direct administration by the central government (BJ and $\mathrm{SH}$ ). The other seven cities (DL, CZ, LY, QD, XM, SuZ, and SZ) are equivalent to provincial capitals in terms of economic development and population sizes. The sum of the population of all the cities is 174.5 million, representing about $13 \%$ of entire population of the nation.

In total, wastewater samples were collected from 36 STPs in the above cities. In most cities, two or three STPs were chosen for sample collection. In LZ, SH, WH, and GZ, however, only one STP in each city was sampled. Most sampled STPs treat wastewater from the urban centers of the cities. The population served by the STPs totals 26.29 million, representing about $21 \%$ of the total population of the cities and $2.0 \%$ of the population of the entire country. The STPs are named as BJ-1 (first STP of Beijing), SuZ-2 (second STP of Suzhou), etc.

Wastewater was collected during two sampling campaigns. Sampling at LZ, XA, WH, LY, SH, and XM were performed between early August and mid-September of 2014, whereas samples from other cities were collected between May and September of 2015. Each STP was sampled for two days (typically one weekend day and one weekday) by collecting 24-h composite samples at the sewage inlets using autosamplers. STPs were asked to program the autosamplers to imbibe $100 \mathrm{~mL}$ of influent at an interval of $1 \mathrm{~h}$. A few STPs (LZ-1, LY-1 and 2, XA-1 and 2, CZ 1-4) did not have autosamplers. At these STPs, $200 \mathrm{~mL}$ of wastewater was collected manually by plant staff every 2 or $4 \mathrm{~h}$ throughout the day and was combined to form a composite sample. Since the time-intervals during sampling at these STPs were large ( 2 or $4 \mathrm{~h}$ ), the possibility that NPS pulses were missed could not be ruled out (Ort et al., 2010). However, manual sampling at shorter intervals was too demanding for the staff and so was not enforced.

At selected STPs, effluent samples were collected in the same manner and at same time as influent samples. Following collection, the samples were acidified on 
spot to $\mathrm{pH}=2$, immediately frozen at the STP, and were then carried back to laboratory with ice and stored at $-20{ }^{\circ} \mathrm{C}$ until analysis. Details of STPs (served population, flow rates) and sampling information are provided in Table $\mathrm{S} 1$.

\subsection{Analysis}

Standards of mephedrone, MDPV, BZP, TFMPP, mCPP, as well as their deuterated internal standards (mephedrone $-d 3, \mathrm{MDPV}_{-d \delta}, \mathrm{BZP}_{-d 7}, \mathrm{TFMPP}_{-d 4}, \mathrm{mCPP}_{-d 8}$ ) were purchased from Cerilliant (Round Rock, TX, USA). Sample pretreatment followed the procedure described in a previous paper (Du et al., 2015), with minor modifications. Briefly, $50 \mathrm{~mL}$ wastewater was filtered using glass fiber to remove solid particles, followed by adding deuterated internal standards for quantification. An Oasis MCX cartridge was conditioned in sequence with $6 \mathrm{~mL}$ methanol $(\mathrm{MeOH}), 4$ $\mathrm{mL}$ deionized water, and $4 \mathrm{~mL}$ deionized water of $\mathrm{pH}=2$. The spiked wastewater was then loaded to the cartridge at a flow rate of 1-2 $\mathrm{mL} \mathrm{min}^{-1}$. Following loading, the cartridge was rinsed sequentially using $3 \mathrm{~mL}$ deionized water, $2 \mathrm{~mL}$ deionized water of $\mathrm{pH}=2$, and $3 \mathrm{~mL} \mathrm{MeOH}$. The cartridge was dried under vacuum and then eluted with $4 \mathrm{~mL}$ of $\mathrm{MeOH}$ and $4 \mathrm{~mL}$ of $5 \% \mathrm{NH}_{3}$ in $\mathrm{MeOH}$ at a flow rate of $1-2 \mathrm{~mL}$ $\min ^{-1}$.The eluate was evaporated to dryness using nitrogen steam and redissolved in $200 \mu \mathrm{L} \mathrm{MeOH} /$ water (1/1, v/v). The sample was further cleaned using a $0.22 \mu \mathrm{m}$ centrifugal filter (VWR International, Radnor, PA, USA).

Compound separation was carried out using a Waters ACQUITY UPLC system (Waters, USA) with a Waters ACQUITY UPLC HSS T3 column (50 mm x $2.1 \mathrm{~mm}$, $1.8 \mu \mathrm{m})$ at an injection volume of $1 \mu \mathrm{L}$. The mobile phase was composed of formic acid/ultrapure water (0.1/100, v/v) (A) and formic acid/ AcN (0.1/100, v/v) (B). The elution gradient was as follows: 0-0.1 min: 0 \% B; 0.1-4.0 min: increase to 90\% $\mathrm{B}$; 4.0-5.0 min: $90 \% \mathrm{~B}$; 5.0-5.2 min: decrease to $0 \% \mathrm{~B}$; 5.2-7.0 min: $0 \% \mathrm{~B}$. The elution was performed at a mobile phase flow rate of $0.4 \mathrm{~mL} / \mathrm{min}$ and a column temperature of $40{ }^{\circ} \mathrm{C}$. Concentrations were determined using an AB Sciex Triple Quad 6500 mass spectrometer (AB SCIEX, USA) equipped with an electrospray interface operating in positive ionization mode. The quantification of MS system was operated in multiple 
reaction monitoring (MRM) mode. Figure S2 shows a representative chromatogram with quantification ions of the substances analyzed.

The instrumental limit of detection (ILOD) and instrument limit of quantification (ILOQ) were estimated considering the concentrations of the compound that gave signals that corresponded to three and ten times the baseline noise ( $\mathrm{S} / \mathrm{N} \geq 3$ and $\mathrm{S} / \mathrm{N} \geq 10$ ), respectively. The method detection limit (MLOD) and method quantification limit (MLOQ) were measured taking into account the whole process of sample preparation by SPE-UPLC-MS/MS. Details of MS parameters, limits of detection (LODs) and limits of quantification (LOQs) of the target compounds were provided in Table 1.

\subsection{Method validation}

The validation was performed in accordance with the International Conference on Harmonization (ICH) guidelines (ICH, 2005) with minor modifications. Recoveries, matrix effects, inter- and intra-day repeatability, and linearity were examined to validate the analytical methods. Recoveries were determined by spiking ultrapure water of $\mathrm{pH}=2$ with target compounds at three concentrations $(2,10$, and 20 ng to $50 \mathrm{~mL}$ water) and then following the same pretreatment procedures. Matrix effects were determined by spiking the low-concentration influent wastewater that had been solid phase extracted at the three concentrations $(2,10,20 \mathrm{ng})$. The differences in concentrations between the spiked and unspiked samples were divided by the spiked concentrations to yield matrix effects. The linearity of the method was assessed by the analysis of standard solutions $(n=10)$ in the concentration range from 0.1 to $200 \mathrm{ng} \mathrm{mL}-1$. Calibration curves were prepared in $\mathrm{MeOH} /$ water $(1 / 1, \mathrm{v} / \mathrm{v})$ and were spiked with the internal standards. The ILOQ was set as the lowest point in the calibration curve of each compound.

The recoveries and matrix effects of target compounds ranged from $77.6 \pm 9.2$ to $100.2 \pm 14.0 \%$ and from $-20.2 \pm 2.4$ to $-15.4 \pm 4.3 \%$, respectively (Table S2). Intra- and inter-day repeatability of method ranged from 1.0 to $4.8 \%$ and from 7.4 to $13.9 \%$, respectively. A procedure blank using ultrapure was included in every 23 wastewater 
samples and followed the same pretreatment procedures. All the target compounds were below detection limits in the blanks. Details of method validation parameters (recovery, matrix effect, linear range, inter- and intra-day precision) were provided in Table S2.

\section{Results and Discussion}

\subsection{Concentrations in influent wastewater}

Mephedrone, TFMPP, and mCPP were below method detection or quantification limits in all the influent wastewater samples, indicating that although these substances were seized from time to time in China, its prevalence is too low to yield detectable concentrations in wastewater. Occurrence of mephedrone and TFMPP was also examined in a number of studies in the literature. Mephedrone was below detection limit in wastewater of large cities in Belgium (van Nuijs et al., 2014), Norway (Reid et al., 2014), Greece (Borova et al., 2015), and Queensland of Australia (Thai et al., 2016). In contrast, mephedrone was detected in wastewater of Cambridge of England (Mwenesongole et al., 2013), Adelaide of Australia (Chen et al., 2013), and two (out of 17) cities in Italy (Castglioni et al., 2015). In particular, exceedingly high concentrations $\left(0.5485 \mathrm{mg} \mathrm{L}^{-1}\right)$ were detected by wastewater of Cambridge (possibly due to dumping) (Mwenesongole et al., 2013). These studies indicate that globally mephedrone abuse is low in general but could be very high in certain cities. TFMPP was detected at concentrations up to $9.8 \mathrm{ng} \mathrm{L}^{-1}$ at a wastewater treatment plants in England (Baker and Kasprzyk-Hordern, 2011) and but not in wastewater of Cambridge (Mwenesongole et al., 2013). TFMPP was detected with weekly loads up to over $20 \mathrm{mg} / 1000$ inhabitants in Adelaide of Australia (Chen et al., 2013). Occurrence of mCPP in wastewater has not been examined in previous studies.

MDPV was detected in 13 out of the 36 STPs. In particular, this substance was detected at $80 \%, 66.7 \%$, and $40 \%$ of the STPs in South, North, and Northwest, respectively (Table 2; Table S3). MDPV was not detected in Northeast (4 STPs), Central China (3 STPs), and Southwest (2 STPs). Detection frequency was also low in 
East China (12.5\%, 1 out of 8 plants). The highest MDPV concentration (observed at XA-1) was only $2.7 \mathrm{ng} \mathrm{L}^{-1}$, indicating low prevalence of the substance in China (Table 2, Table S3). Occurrence of MDPV was examined in only three studies in the literature. MDPV was not detected in wastewater from Antwerp and Brussels in Belgium (van Nuijs et al., 2014). MDPV was detected at 2 out of 10 cities in Finland and at Adelaide of Australia (Chen et al., 2013; Kankaanpää et al., 2014).

BZP was quantifiable at all the STPs examined in this study (Table 2), indicating widespread occurrence of this substance in wastewater in China. Influent BZP concentrations ranged from $1.5 \pm 0.9 \mathrm{ng} \mathrm{L} \mathrm{L}^{-1}$ (CZ-2) to $38.4 \pm 0.8 \mathrm{ng} \mathrm{L}^{-1}$ (BJ-3). Highest BZP concentrations were observed in Beijing and Taiyuan (average concentrations of the cities $>30 \mathrm{ng} \mathrm{L}^{-1}$ ). BZP was not detected in wastewater of Cambridge (Mwenesongole et al., 2013) and Greece (Borova et al., 2015). In contrast, Baker and Kasprzyk-Hordern (2011) reported a BZP concentration of $37.6 \mathrm{ng} \mathrm{L}{ }^{-1}$ (close to highest concentration observed in this study) at a wastewater treatment plants in England. BZP was also detected at three STPs in Adelaide of Australia (Chen et al., 2013). However, exact concentrations at the three STPs were not reported in that study.

\subsection{Apparent removal of MDPV and BZP}

Effluent wastewater samples were collected from 16 STPs in 8 cities. MDPV were quantifiable in effluents at most STPs where influent concentrations were above quantification limits (BJ-1, CZ-1 and 3, SH-1, GZ-1, SZ-1). Effluent MDPV concentrations ranged from $0.5{\text { centrat } \mathrm{L}^{-1} \text { (SH-1) to } 1.6 \mathrm{~s} \text { ranged }}^{-1}$ (BJ-1) (Table 2, Table S3). BZP were below detection or quantification limits in effluents at all STPs examined, although BZP concentrations in influents were greater than $10 \mathrm{ng} \mathrm{L}^{-1}$ at most STPs. Apparent removal rates of MDPV were derived by dividing the differences between influent and effluent concentrations by the influent concentrations. To calculate the apparent removal rates of BZP, effluent concentrations were set as zero if the concentrations were below the detection limit or as half of the quantification limit if the concentrations were below the quantification 
limit but greater than the detection limit. BZP removal was greater than $95 \%$ at all but one STP (Figure 1). At this STP (CZ-2), the removal rate was still quite high, $60 \%$. These results indicate that BZP removal by wastewater treatment was nearly complete. In contrast, MDPV removal rates ranged from $6.8 \%$ at SZ-1 to $21.2 \%$ at $\mathrm{CZ}-3$, indicating that removal by the wastewater treatment processes was poor and MDPV may enter receiving waters in large quantities in the case of high occurrence of the substance in influent wastewater. To our knowledge, this is the first report on MDPV and BZP removal during wastewater treatment.

\subsection{Loads of MDPV and BZP}

The daily mass load of each target substance per 1000 inhabitants at a specific STP was calculated using the following equation:

Influent load of a chemical residue $\left(\frac{\mathrm{mg}}{1000 \cdot \text { day }}\right)=\frac{\text { Concentration of a chemical residue }(\mathrm{ng} / \mathrm{L}) \times \operatorname{Influent} \text { flow }(\mathrm{L} / \mathrm{d})}{\frac{\text { Population served }}{1000}} \times \frac{1}{10^{6}}\left(\frac{\mathrm{mg}}{\mathrm{ng}}\right)$

Concentration of the substance was measured using the analytical methods described above. Influent flows on each day of sampling were provided by each respective STP. Populations served by STPs were either obtained from the STPs or based on the most recent census data of the service areas (Table S1).

There was no significant difference in MDPV loads between weekday and weekend. Highest MDPV loads were observed at XA-1 (1.6 mg/1000inh/d) and XA-2 $(0.6 \pm 0.2 \mathrm{mg} / 1000 \mathrm{inh} / \mathrm{d})$ of $\mathrm{Xi}-\mathrm{An}$ in Northwest China and BJ-3 (0.6 \pm 0.9 $\mathrm{mg} / 1000 \mathrm{inh} / \mathrm{d}$ ) of Beijing in North China. At the other 10 STPs where MDPV were detectable, MDPV loads ranged from $0.1 \pm 0.1 \mathrm{mg} / 1000 \mathrm{inh} / \mathrm{d}$ (CZ-3) to $0.4 \pm 0.04$ mg/1000inh/d (CZ-1) (Figure 2, Table S4). The detection frequencies and loads of MDPV were much lower than those of methamphetamine and ketamine in wastewater across China (Du et al., 2015). Du et al. (2015) reported an average methamphetamine load of $70.4( \pm 47.4) \mathrm{mg} / 1000 \mathrm{inh} / \mathrm{d}$ in wastewater of major Chinese cities. Ketamine loads were found to be greater than $10 \mathrm{mg} / 1000 \mathrm{inh} / \mathrm{d}$ in wastewater of majority of the cities. In wastewater of some cities in South China (SZ, WH, and NN), ketamine 
loads were greater than $50 \mathrm{mg} / 1000 \mathrm{inh} / \mathrm{d}$. Thus, it is clear that although MDPV is used at some Chinese cities, its prevalence is far less than that of the primary drugs of abuse. Furthermore, MDPV loads in Chinese cities were far lower than some cities in Europe and Australia (Chen et al., 2013; Kankaanpää et al., 2014).

Like MDPV, no significant difference in BZP loads between weekday and weekend was observed. BZP loads ranged from $0.5 \pm 0.3 \mathrm{mg} / 1000 \mathrm{inh} / \mathrm{d}(\mathrm{CZ}-2)$ to 17.1 mg/1000inh/d (XA-1) (Figure 2, Table S4). At the majority of the STPs, BZP loads fell within the range of 3-10 mg/1000inh/d. No clear geographic pattern in BZP loads can be seen from Figure 2, although it appears that the average BZP load of the northern regions (North, Northeast, and Northwest China) was greater than that of the other regions of the country. BZP loads were in general also much lower than those of methamphetamine. In contrast, in the 17 STPs where both ketamine and BZP concentrations were determined, BZP loads were greater than ketamine loads at 5 STPs. There were only two studies in the literature that reported BZP loads in Australia. Weekly BZP loads were reported to be as high as over $200 \mathrm{mg} / 1000 \mathrm{inh} / \mathrm{w}$ (which translate to about $30 \mathrm{mg} / 1000 \mathrm{inh} / \mathrm{d}$ ) (Chen et al., 2013). The other study captured the extent of daily BZP use at an annual music festival, and showed that BZP was detected on five days in 2010 (average load $20 \mathrm{mg} / 1000 \mathrm{inh} / \mathrm{d}$ ) but on only one day (the last day) in 2011 at a significantly lower level $(6.7 \mathrm{mg} / 1000 \mathrm{inh} / \mathrm{d})$ (Lai et al., 2013).

Widespread detection and overall moderate loads of BZP in wastewater of the major Chinese cities indicate that its occurrence cannot be overlooked. However, one must caution to equate widespread occurrence of BZP in wastewater to widespread abuse of this substance, as BZP and other piperazines may come as intermediates or metabolites of other medicines (Chang et al., 2015). Legal sources of BZP are hard to estimate at this point. According the Bureau of Narcotics of China (personal communication), BZP was found only in seized tablets. Among the seized tablet samples (around 4000-5000 samples per year) collected from across China, BZP was identified in only $0.1 \%$ of the samples. Furthermore, in nearly all the tablet samples 
where BZP was identified, TFMPP was found as well, usually at a mass ratio of 1:2. Thus, the fact that TFMPP was not detectable in the wastewater of all the STPs examined would rather suggest BZP abuse was also negligible from most cities in China. However, one must also be careful to draw such a conclusion as excretion rates and stability in wastewater of TFMPP and BZP may differ dramatically. The excretion rate of BZP examined in only one study in the literature (Antia et al., 2009), while the excretion rate of TFMPP has not been reported in literature. Future research is warranted to address these issues and confirm whether BZP in wastewater in China is mainly from abuse or legal sources.

\section{Conclusions}

A nationwide reconnaissance was carried to investigate the occurrence of two synthetic cathinones (mephedrone and MDPV) and three piperazines (BZP, TFMPP, and $\mathrm{mCPP}$ ) in wastewater of major Chinese cities. Mephedrone, TFMPP, and mCPP were not detected in wastewater at any cities. MDPV was detected in about $40 \%$ of cities examined, indicating moderately widespread abuse of the substance, albeit at low levels. BZP was detected at all STPs examined, indicating widespread occurrence of the substance in wastewater of the major cities sampled. However, whether this indicates widespread abuse of BZP is yet to be confirmed, as BZP may also come from legal sources in China.

\section{Acknowledgements}

This work is based on work funded by the National Science Foundation of China (Grant No. 41371442). The authors wish to thank all the personnel at the 36 sewage treatment plants who assisted in wastewater sampling.

\section{Appendix A. Supplementary data}

Locations of cities sampled (Figure S1); chromatogram with quantification ions of the substances analyzed (Figure S2); sampling information (Table S1); validation parameters of analytical methods (Table S2); MDPV and BZP concentrations on each 
sampling dates (Table S3); MDPV and BZP loads (Table S4).

\section{References}

Andres-Costa MJ, Rubio-Lopez N, Morales Suarez-Varela M, Pico Y. Occurrence and removal of drugs of abuse in Wastewater Treatment Plants of Valencia (Spain). Environ Pollut 2014; 194: 152-62.

Antia U, Lee HS, Kydd RR, Tingle MD, Russell BR. Pharmacokinetics of 'party pill' drug N-benzylpiperazine (BZP) in healthy human participants. Forensic Sci Int 2009; 186 : 63-7.

Baker DR, Barron L, Kasprzyk-Hordern B. Illicit and pharmaceutical drug consumption estimated via wastewater analysis. Part A: chemical analysis and drug use estimates. Sci Total Environ 2014; 487: 629-41.

Baker DR, Kasprzyk-Hordern B. Multi-residue analysis of drugs of abuse in wastewater and surface water by solid-phase extraction and liquid chromatography-positive electrospray ionisation tandem mass spectrometry. J Chromatogr A 2011; 1218: 1620-31.

Banta-Green CJ, Field JA, Chiaia AC, Sudakin DL, Power L, de Montigny L. The spatial epidemiology of cocaine, methamphetamine and 3,4-methylenedioxymethamphetamine (MDMA) use: a demonstration using a population measure of community drug load derived from municipal wastewater. Addiction 2009; 104: 1874-80.

Bartelt-Hunt SL, Snow DD, Damon T, Shockley J, Hoagland K. The occurrence of illicit and therapeutic pharmaceuticals in wastewater effluent and surface waters in Nebraska. Environ Pollut 2009; 157: 786-91.

Berset JD, Brenneisen R, Mathieu C. Analysis of llicit and illicit drugs in waste, surface and lake water samples using large volume direct injection high performance liquid chromatography--electrospray tandem mass spectrometry (HPLC-MS/MS). Chemosphere 2010; 81: 859-66.

Bisceglia KJ, Roberts AL, Schantz MM, Lippa KA. Quantification of drugs of abuse in municipal wastewater via SPE and direct injection liquid chromatography mass spectrometry. Anal Bioanal Chem 2010; 398: 2701-12.

Borova VL, Gago-Ferrero P, Pistos C, Thomaidis NS. Multi-residue determination of 10 selected new psychoactive substances in wastewater samples by liquid chromatography-tandem mass spectrometry. Talanta 2015; 144: 592-603.

Bramness JG, Reid MJ, Solvik KF, Vindenes V. Recent trends in the availability and use of amphetamine and methamphetamine in Norway. Forensic Sci Int 2015; 246: 92-7.

Brewer AJ, Ort C, Banta-Green CJ, Berset JD, Field JA. Normalized diurnal and between-day trends in illicit and legal drug loads that account for changes in population. Environ Sci Technol 2012; 46: 8305-14. 
Castiglioni S, Borsotti A, Senta I, Zuccato E. Wastewater analysis to monitor spatial and temporal patterns of use of two synthetic recreational drugs, ketamine and mephedrone, in Italy. Environ Sci Technol 2015; 49: 5563-70.

Chang J, Hao H, Li H, Wang F, Hou X, Wang R, The detection of mCPP、TFMPP in blood samples by gas chromatographic mass spectrum and gas chromatography with nitrogen phosphorus detection, Chin J Forensic Med 2015; 30(2): 121-124 (in Chinese).

Chen C, Kostakis C, Irvine RJ, White JM. Increases in use of novel synthetic stimulant are not directly linked to decreased use of 3,4-methylenedioxy-N-methylamphetamine (MDMA). Forensic Sci Int 2013; 231: 278-83.

Du P, Li K, Li J, Xu Z, Fu X, Yang J, et al. Methamphetamine and ketamine use in major Chinese cities, a nationwide reconnaissance through sewage-based epidemiology. Water Res 2015; 84: 76-84.

Heuett NV, Ramirez CE, Fernandez A, Gardinali PR. Analysis of drugs of abuse by online SPE-LC high resolution mass spectrometry: communal assessment of consumption. Sci Total Environ 2015; 511: 319-30.

ICH. International Conference on Harmonization tripartite guideline (2005) ICH topic Q2.Validation of analytical procedures: text and methodology; 2005 [Geneva].

Irvine RJ, Kostakis C, Felgate PD, Jaehne EJ, Chen C, White JM. Population drug use in Australia: a wastewater analysis. Forensic Sci Int 2011; 210: 69-73.

Kankaanpää A, Ariniemi K, Heinonen M, Kuoppasalmi K, Gunnar T. Use of illicit stimulant drugs in Finland: a wastewater study in ten major cities. Sci Total Environ 2014; 487: 696-702.

Karolak S, Nefau T, Bailly E, Solgadi A, Levi Y. Estimation of illicit drugs consumption by wastewater analysis in Paris area (France). Forensic Sci Int 2010; 200: 153-60.

Khan U, van Nuijs AL, Li J, Maho W, Du P, Li K, et al. Application of a sewage-based approach to assess the use of ten illicit drugs in four Chinese megacities. Sci Total Environ 2014; 487: 710-21.

Kim KY, Lai FY, Kim HY, Thai PK, Mueller JF, Oh JE. The first application of wastewater-based drug epidemiology in five South Korean cities. Sci Total Environ 2015; 524-525: 440-6.

Kinyua J, Covaci A, Maho W, McCall AK, Neels H, van Nuijs AL. Sewage-based epidemiology in monitoring the use of new psychoactive substances: Validation and application of an analytical method using LC-MS/MS. Drug Test Anal 2015; 7: 812-8.

Lai FY, Anuj S, Bruno R, Carter S, Gartner C, Hall W, et al. Systematic and day-to-day effects of chemical-derived population estimates on wastewater-based drug epidemiology. Environ Sci Technol 2015; 49: 999-1008.

Lai FY, Bruno R, Leung HW, Thai PK, Ort C, Carter S, et al. Estimating daily and diurnal variations of illicit drug use in Hong Kong: a pilot study of using wastewater analysis in an Asian metropolitan city. Forensic Sci Int 2013; 233: 126-32. 
Lai FY, Thai PK, O'Brien J, Gartner C, Bruno R, Kele B, et al. Using quantitative wastewater analysis to measure daily usage of conventional and emerging illicit drugs at an annual music festival. Drug Alcohol Rev 2013; 32: 594-602.

Li J, Hou L, Du P, Yang J, Li K, Xu Z, et al. Estimation of amphetamine and methamphetamine uses in Beijing through sewage-based analysis. Sci Total Environ 2014; 490: 724-32.

Loganathan B, Phillips M, Mowery H, Jones-Lepp TL. Contamination profiles and mass loadings of macrolide antibiotics and illicit drugs from a small urban wastewater treatment plant. Chemosphere 2009; 75: 70-7.

Mackulak T, Skubak J, Grabic R, Ryba J, Birosova L, Fedorova G, et al. National study of illicit drug use in Slovakia based on wastewater analysis. Sci Total Environ 2014; 494-495: $158-65$.

Metcalfe C, Tindale K, Li H, Rodayan A, Yargeau V. Illicit drugs in Canadian municipal wastewater and estimates of community drug use. Environ Pollut 2010; 158: 3179-85.

Mwenesongole EM, Gautam L, Hall SW, Waterhouse JW, Cole MD. Simultaneous detection of controlled substances in waste water. Analytical Methods 2013; 5: 3248.

Office of China National Narcotic Control Commission. Annual Report on Drug Control in China. Beijing: China National Narcotics Control Commission; 2014.

Office of China National Narcotic Control Commission. Annual Report on Drug Control in China. Beijing: China National Narcotics Control Commission; 2015.

Ort C, Lawrence MG, Rieckermann J, Joss AA. Sampling for Pharmaceuticals and Personal Care Products (PPCPs) and Illicit Drugs in Wastewater Systems: Are Your Conclusions Valid? A Critical Review. Environ Sci Technol 2010; 44: 6024-35.

Östman M, Fick J, Näsström E, Lindberg RH. A snapshot of illicit drug use in Sweden acquired through sewage water analysis. Sci Total Environ 2014; 472: 862-71.

Reid MJ, Derry L, Thomas KV. Analysis of new classes of recreational drugs in sewage: synthetic cannabinoids and amphetamine-like substances. Drug Test Anal 2014; 6: 72-9.

Repice C, Dal Grande M, Maggi R, Pedrazzani R. Licit and illicit drugs in a wastewater treatment plant in Verona, Italy. Sci Total Environ 2013; 463-464: 27-34.

Thai PK, Lai FY, Edirisinghe M, Hall W, Bruno R, O'Brien JW, et al. Monitoring temporal changes in use of two cathinones in a large urban catchment in Queensland, Australia. Sci Total Environ 2016; 545-546: 250-5.

UNODC.World drug report. New York: UNODC; 2013.

UNODC.World drug report. New York: UNODC; 2015.

van Nuijs AL, Gheorghe A, Jorens PG, Maudens K, Neels H, Covaci A. Optimization, validation, and the application of liquid chromatography-tandem mass spectrometry for the analysis of new drugs of abuse in wastewater. Drug Test Anal 2014; 6: 861-7.

van Nuijs AL, Pecceu B, Theunis L, Dubois N, Charlier C, Jorens PG, et al. Cocaine and metabolites in waste and surface water across Belgium. Environ Pollut 2009; 157: 123-9. 
Yargeau V, Taylor B, Li H, Rodayan A, Metcalfe CD. Analysis of drugs of abuse in wastewater from two Canadian cities. Sci Total Environ 2014; 487: 722-30.

Zuccato E, Chiabrando C, Castiglioni S, Calamari D, Bagnati R, Schiarea S, et al. Cocaine in surface waters: a new evidence-based tool to monitor community drug abuse. Environ Health 2005; 4: 1-7.

Zuccato E, Chiabrando C, Castiglioni S, Bagnati R, Fanelli R. Estimating community drug abuse by wastewater analysis. Environ Health Perspect 2008; 116: 1027-32. 
Table 1. Analysis conditions, instrument and method limits of detection (ILOD, MLOD), instrument and method limits of quantification (ILOQ, MLOQ) of NPS and their internal standards.

\begin{tabular}{|c|c|c|c|c|c|c|c|c|c|c|}
\hline \multirow{2}{*}{$\begin{array}{l}\text { NPS and } \\
\text { Internal } \\
\text { standard }\end{array}$} & \multirow{2}{*}{$\begin{array}{c}\text { Precursor } \\
\text { ion } \\
\mathbf{m} / \mathbf{z}(\mathbf{D a})\end{array}$} & \multicolumn{2}{|c|}{ Quantifier } & \multicolumn{2}{|c|}{ Qualifier } & \multirow{2}{*}{$\begin{array}{l}\text { Retention } \\
\text { time (min) }\end{array}$} & \multicolumn{2}{|c|}{ LOD } & \multicolumn{2}{|c|}{ LOQ } \\
\hline & & $\begin{array}{l}\text { Product ion } \\
\quad(\mathbf{m} / \mathbf{z})\end{array}$ & $\begin{array}{c}\text { Collision energy } \\
\text { (V) }\end{array}$ & $\begin{array}{l}\text { Product ion } \\
\quad(\mathbf{m} / \mathbf{z})\end{array}$ & $\begin{array}{l}\text { Collision } \\
\text { energy (V) }\end{array}$ & & $\begin{array}{l}\text { ILOD } \\
\text { ng/mL }\end{array}$ & $\begin{array}{c}\text { MLOD } \\
\text { ng/L }\end{array}$ & $\begin{array}{l}\text { ILOQ } \\
\text { ng/mL }\end{array}$ & $\begin{array}{c}\text { MLOQ } \\
\text { ng/L }\end{array}$ \\
\hline Mephedrone & 178.1 & 160.0 & 19 & 145.2 & 30 & 1.60 & 0.1 & 0.4 & 0.5 & 2.0 \\
\hline Mephedrone-D3 & 181.1 & 163.0 & 19 & 148.2 & 29 & 1.60 & - & - & - & - \\
\hline MDPV & 276.1 & 126.1 & 34 & 135.0 & 38 & 1.89 & 0.05 & 0.2 & 0.1 & 0.4 \\
\hline MDPV-D8 & 284.1 & 134.2 & 36 & 135.0 & 39 & 1.89 & - & - & - & - \\
\hline $\mathrm{BZP}$ & 177.1 & 91.0 & 32 & 85.1 & 22 & 1.04 & 0.1 & 0.4 & 0.5 & 2.0 \\
\hline BZP-D7 & 184.1 & 98.0 & 32 & 85.0 & 24 & 1.03 & - & - & - & - \\
\hline TFMPP & 231.0 & 188.0 & 33 & 119.0 & 42 & 1.98 & 0.1 & 0.4 & 0.5 & 2.0 \\
\hline TFMPP-D4 & 235.1 & 190.0 & 32 & 121.1 & 44 & 1.98 & - & - & - & - \\
\hline $\mathrm{mCPP}$ & 197.0 & 154.1 & 27 & 119.2 & 35 & 1.79 & 0.1 & 0.4 & 0.5 & 2.0 \\
\hline mCPP-D8 & 205.1 & 158.1 & 31 & 123.1 & 38 & 1.79 & - & - & - & - \\
\hline
\end{tabular}


Table 2. Mean influent and effluent concentrations of MDPV and BZP (ng L $\mathrm{L}^{-1}$ ). Method LOQ (MLOQ) for MDPV and BZP were 0.4 and 2.0 ng $\mathrm{L}^{-1}$, respectively.

\begin{tabular}{|c|c|c|c|c|c|c|c|c|c|}
\hline \multirow{2}{*}{ City } & \multirow{2}{*}{ STP } & \multicolumn{2}{|c|}{ MDPV } & \multicolumn{2}{|c|}{ BZP } & \multirow{2}{*}{ City } & \multirow{2}{*}{ STP } & MDPV & BZP \\
\hline & & Influent & Effluent & Influent & Effluent & & & \multicolumn{2}{|c|}{ Influent } \\
\hline \multirow{2}{*}{ Yinchuan } & YC-1 & ND & ND & $14.9 \pm 1.9$ & $0.5 \pm 0.7$ & \multirow{2}{*}{ Haerbin } & HRB-1 & ND & $25.8 \pm 1.5$ \\
\hline & $\mathrm{YC}-2$ & ND & ND & $8.7 \pm 2.1$ & $<$ MLOQ & & HRB-2 & ND & $16.8 \pm 7.9$ \\
\hline \multirow{3}{*}{ Beijing } & BJ-1 & $1.9 \pm 0.4$ & $1.6 \pm 0.5$ & $32.8 \pm 7.2$ & $<$ MLOQ & \multirow{2}{*}{ Dalian } & DL-1 & ND & $10.6 \pm 2.8$ \\
\hline & BJ-2 & ND & ND & $21.3 \pm 13.8$ & ND & & DL-2 & ND & $5.2 \pm 0.1$ \\
\hline & BJ-3 & $2.5 \pm 3.6$ & ND & $38.4 \pm 0.8$ & $<$ MLOQ & Lanzhou & LZ-1 & ND & 22.0 \\
\hline \multirow{4}{*}{ Changzhi } & CZ-1 & $1.3 \pm 0.1$ & $1.2 \pm 0.1$ & $18.9 \pm 1.3$ & $<$ MLOQ & \multirow{2}{*}{ Xi'an } & XA-1 & 2.7 & 29.1 \\
\hline & $\mathrm{CZ}-2$ & ND & ND & $1.5 \pm 0.9$ & $<$ MLOQ & & XA-2 & $1.5 \pm 0.4$ & $15.3 \pm 9.0$ \\
\hline & CZ-3 & $0.5 \pm 0.8$ & $0.7 \pm 0.6$ & $23.0 \pm 5.1$ & $<$ MLOQ & \multirow{2}{*}{ Taiyuan } & TY-1 & ND & $32.7 \pm 3.8$ \\
\hline & CZ-4 & $0.6 \pm 1.0$ & ND & $18.9 \pm 1.9$ & $<$ MLOQ & & TY-2 & $0.6 \pm 1.0$ & $33.2 \pm 2.4$ \\
\hline Wuhan & WH-1 & $\mathrm{ND}$ & $\mathrm{ND}$ & 6.4 & $\mathrm{ND}$ & \multirow{2}{*}{ Luoyang } & LY-1 & $\mathrm{ND}$ & 9.7 \\
\hline Shanghai & SH-1 & $1.2 \pm 0.1$ & $0.5 \pm 0.7$ & $9.2 \pm 1.7$ & $\mathrm{ND}$ & & LY-2 & ND & 17.8 \\
\hline \multirow{2}{*}{ Xiamen } & XM-1 & ND & $\mathrm{ND}$ & 9.3 & ND & \multirow{2}{*}{ Qingdao } & QD-1 & $\mathrm{ND}$ & $16.5 \pm 7.0$ \\
\hline & XM-2 & ND & ND & $21.0 \pm 0.4$ & ND & & QD-2 & ND & $25.4 \pm 0.1$ \\
\hline Guangzhou & GZ-1 & $0.6 \pm 0.8$ & $0.5 \pm 0.7$ & $9.5 \pm 0.1$ & $\mathrm{ND}$ & \multirow{3}{*}{ Suzhou } & SuZ-1 & ND & $9.7 \pm 1.5$ \\
\hline \multirow{6}{*}{ Shenzhen } & SZ-1 & $1.4 \pm 0.05$ & 1.3 & $21.0 \pm 1.7$ & $<$ MLOQ & & SuZ-2 & ND & $18.2 \pm 5.3$ \\
\hline & SZ-2 & ND & ND & $11.7 \pm 5.9$ & ND & & SuZ-3 & ND & $9.0 \pm 1.8$ \\
\hline & & & & & & \multirow{2}{*}{ Nanning } & NN-1 & $1.0 \pm 0.1$ & $8.2 \pm 0.2$ \\
\hline & & & & & & & $\mathrm{NN}-2$ & $1.1 \pm 0.1$ & $8.5 \pm 0.9$ \\
\hline & & & & & & \multirow{2}{*}{ Chengdu } & CD-1 & ND & $18.4 \pm 2.6$ \\
\hline & & & & & & & CD-1 & ND & $19.1 \pm 1.0$ \\
\hline
\end{tabular}

ND $=$ not detected (below method limits of detection (MLOD) 


\section{Figure Captions}

Figure 1. Apparent removal rates of MDPV and BZP.

Figure 2. Average loads of MDPV and BZP at STPs. 


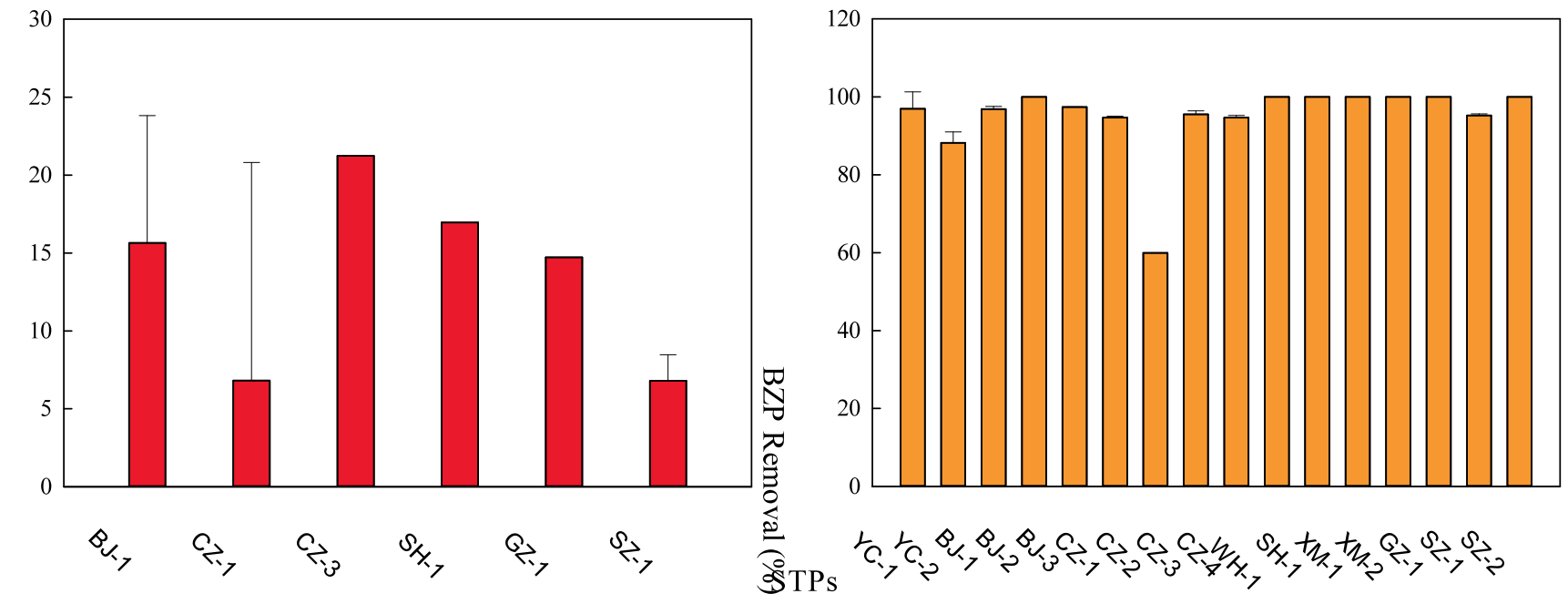

Figure 1. 


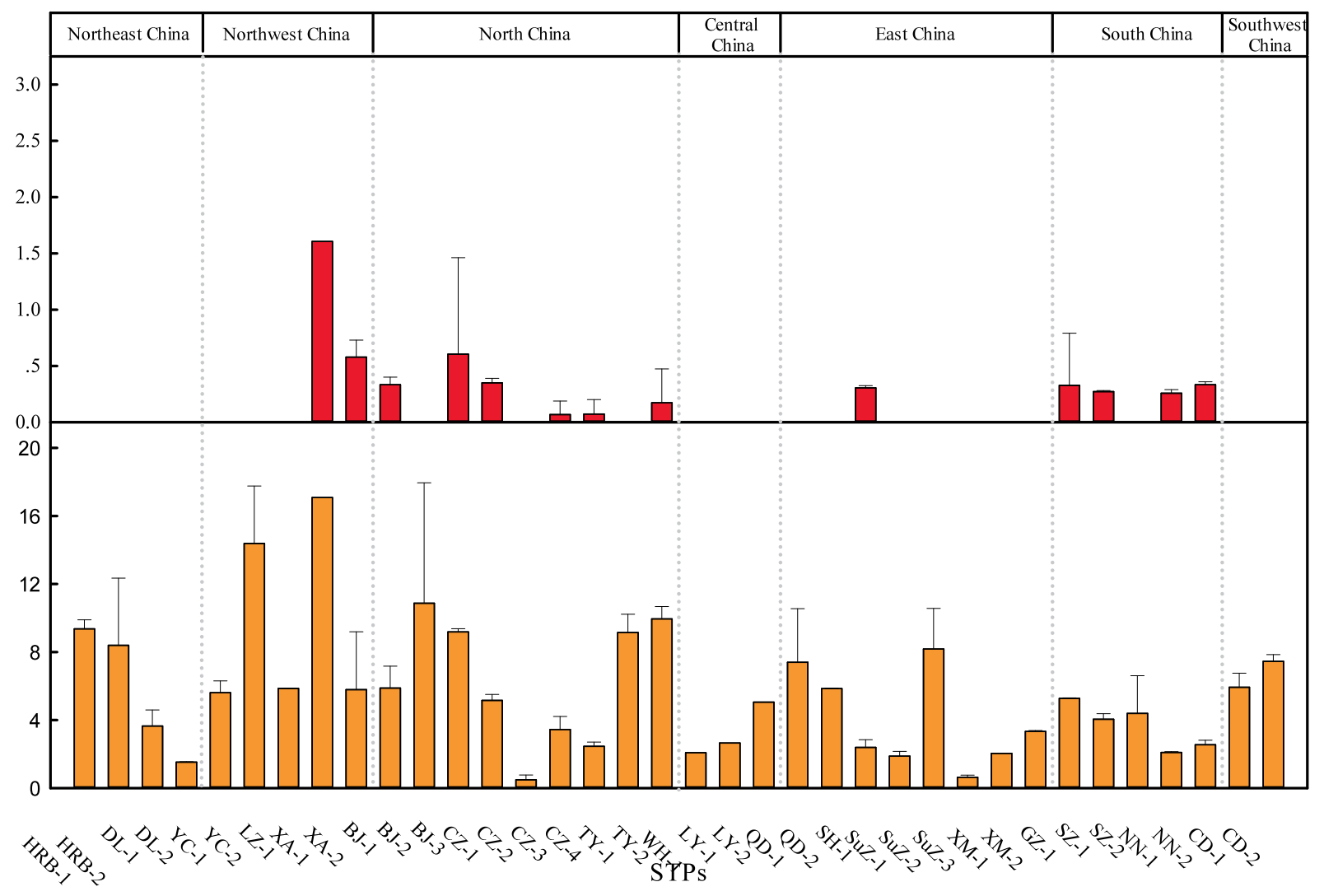

Figure 2 


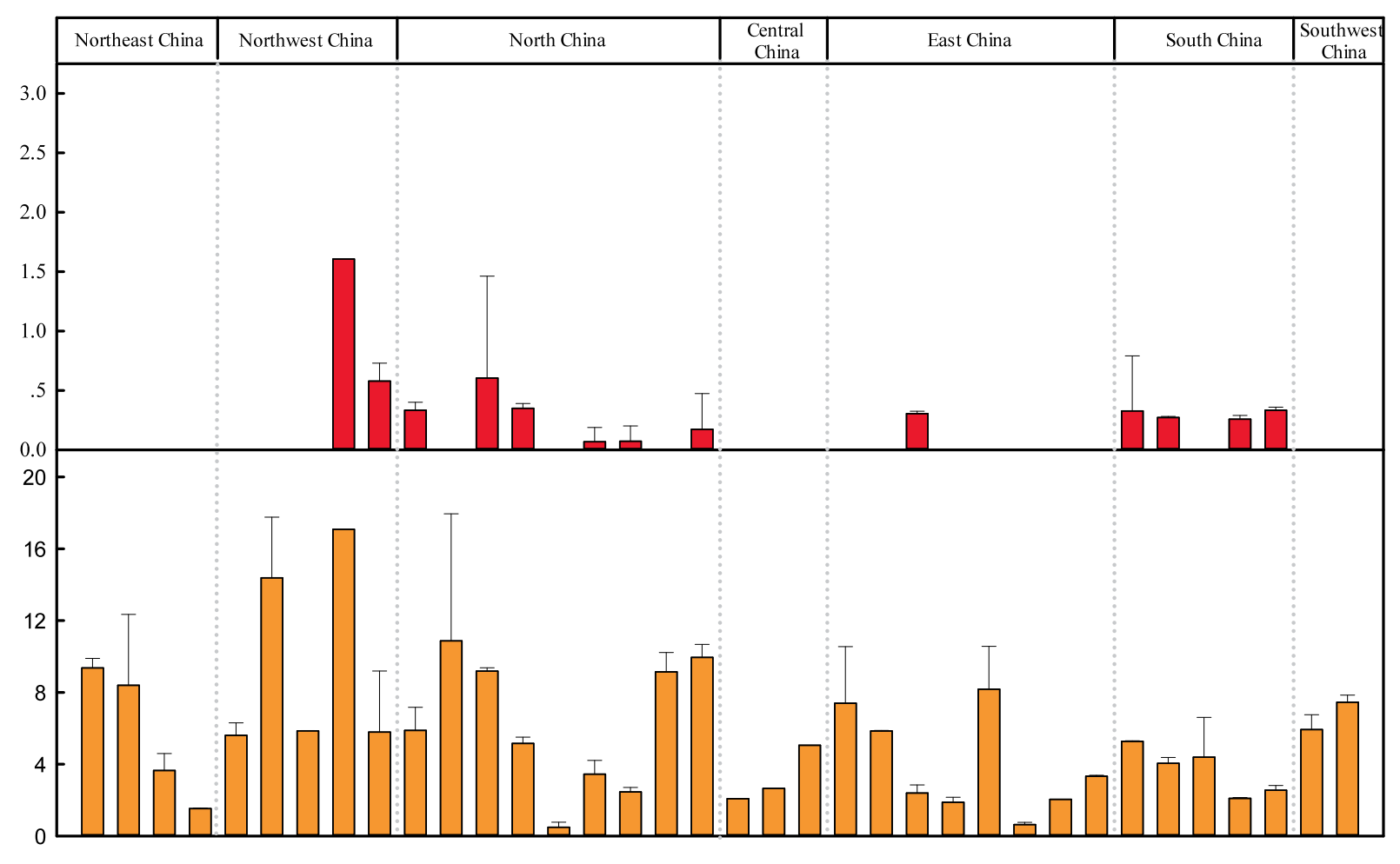

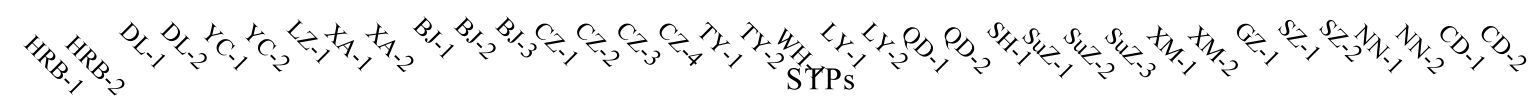

